\title{
Experimental evaluation of effects of steel and glass fibers on engineering properties of concrete
}

\author{
Jalal Akbari*, Amirhossein Abed \\ Bu-Ali Sina University, Hamedan, Iran \\ j.akbari@basu.ac.ir, bttps://orcid.org/0000-0001-9713-8652 \\ abedi.amirhosein@gmail.com
}

\begin{abstract}
This paper experimentally investigates the effect of steel and glass fibers on the engineering properties of concrete. To achieve this, $0.3 \%, 0.6 \%$, and $0.9 \%$ by volume fraction of steel and glass fibers are added in concrete mixtures with water-to-cement (W/C) ratios 0.35 and 0.45 . For each ratio of water to cement, 21 cubic samples for compressive strength tests, 14 cylindrical samples for tension strength tests, and also 14 prismatic samples for three-point flexural strength tests were prepared. The experimental results show that adding $0.3 \%$ to $0.9 \% \%$ steel fibers for concrete increases simultaneously the compressive, tension, and also flexural strengths in comparison with plain concrete. Adding glass fibers only between $0.3 \%$ to $0.6 \%$ increases the compressive strength. The results reveal that the best range for reinforcing concrete with steel fiber is $0.3 \%$ to $0.9 \%$, and glass fiber is $0.3 \%$ to $0.6 \%$ by volume fraction of fiber to improve the engineering strengths concrete. As a rule of thumb, the tension and flexural strengths of concrete could be explained as $8 \%$ and $13 \%$ of the compressive strength, respectively.
\end{abstract}

KEYwORDS. Steel fibers; Glass fibers; Compressive strength; Tension strength; Flexural strength; Mechanical properties; Engineering properties.

\section{OPEN ACCESS}

Citation: Akbari, J., Abed, A., Experimental evaluation of effects of steel and glass fibers on engineering properties of concrete, Frattura ed Integrità Strutturale, 54 (2020) 116-127.

Received: 28.05 .2020

Accepted: 31.07 .2020 Published: 01.10 .2020

Copyright: (C) 2020 This is an open access article under the terms of the CC-BY 4.0, which permits unrestricted use, distribution, and reproduction in any medium, provided the original author and source are credited.

\section{INTRODUCTION}

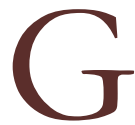

enerally, concrete is a weak material in tension in which cracks develop during hardening and shrinkage stages due to drying and cracking. Most of the problem occurs when cracking is observed on the concrete surface and, generally causes an unpleasant surface on the concrete. These cracks are usually the pores for infiltration of salt and water into the concrete that increases the probability of rebar's corrosion. If this weakness is remedied, the maintenance costs of the concrete structures would be reduced, and the useful lifetime of concrete structures will be extended. Nowadays, fibers are competitive options to improve the mechanical properties of concrete. The resistance of the concrete increases due to the plastic shrinkage's formation in concrete when the fibers are uniformly spread in concrete in all directions. On 
the other hand, the uniform spreading of the fibers does not allow the initiation of the small cracks and prevents forming large cracks. As well, fibers in the cementitious matrix decrease cracking width, increase flexural, tensile strengths, and increase the fracture toughness of concrete.

Steel fibers reinforced concrete (SFRC) is an advanced composite material that combines plain concrete with steel fibers with various lengths and diameters [[1],[2]]. SFRC is one of the most important materials that enhance the performance of concrete mainly after cracking under stresses [[3],[4],[5]]. In recent years, the researches on the effects of steel fibers are mainly focused on tension, shear, and flexural strengths. Liu et al. [[6]] studied tensile properties of glass fiber; Gansenan et al. [[7]] examined the influence of steel fibers on tension stiffening of concrete. Ashour et al. [[8]] and Kwak et al. [[9]] studied the shear behavior of high-strength fiber reinforced concrete beams. Besides, many investigations are accomplished on the enhancement of the flexural behavior of concrete with fibers. Soutsos and Lampropoulos [[10]] and Aldossari et al. [[11]] studied the effect of steel fiber on the flexural performance of normal and high strength concrete. Wile and ParraMontesions [[12]], Meng \& Khayat [[13]] studied the effect of fibers on the flexural behavior of ultrahigh-performance concrete. Kushartomo and Ivan [[14]] examined the effect of glass fiber on flexural, compressive, and splitting strengths of reactive powder concrete. Many investigations were conducted on the effects of fibers on combined stresses. Chalioris [[15]] proposed an analytical approach for the minimum fiber factor required for steel fibrous concrete beams under combined shear and flexural strengths. Yoo et al. [[16]] studied the effect of fiber length and placement method on flexural behavior, tension- softening curve, and fiber distribution characteristics of ultrahigh-performance concrete. As well, many types of research have been carried out on improvement of mechanical properties using various fibers in concrete e.g.; Sivakumar and Santhanam [[17]]; Xu and Shi [[18]]; Chandramouli et al. [[19]]; Nili and Afroughsabet [[20]]; Bhikshma and Manipal [[21]]; Etchevery and Barbosa [[22]]; Kamal et al. [[23]]; Ashik and Sharma [[24]]; Saba et al. [[25]]; Ibrahim [[26]] and Ahmadi et.al [[27]].

The surveys mentioned above did not comprehensively describe how much fibers should be added into concrete to improve the tensile, compressive, and flexural strengths simultaneously. To the knowledge of the authors, comprehensive studies have not yet been conducted to provide a practical guideline of the best ranges for adding various fibers to concrete and presenting applicable relation between different strengths. In this paper, the effects of steel and glass fibers on the mechanical properties of concrete are experimentally investigated. For this purpose, normal concrete with water to cement ratio of 0.45 and high strength concrete with water to cement ratio equal to 0.35 were considered. To perform the experimental tests of each water-cement ratio, for compressive strength, 21 cubic specimens, for tensile strength test 14 cylindrical specimens, and finally, for flexural strength test, 14 prismatic specimens are designed.

\section{Procedures OF RESEARCH}

7 o prepare normal and high strength concretes, the water-to-cement ratios were selected to 0.45 and 0.35 . For each water-to-cement ratio, seven concrete mixtures, including concrete without fiber, concrete containing $0.3 \%, 0.6 \%$ and $0.9 \%$ by volume fraction of steel and also glass fibers, were prepared. In all mixtures, only the effects of waterto-cement ratios, percentage of fibers, and the type of fibers were investigated. Based on the experiences of the authors, the volume of the fibers is selected less than $1 \%$. The reason is that the inhomogeneous spreading of fibers in concrete will occur when the percentage of fibers exceeds more than $1 \%$. Therefore, the volume fractions of the fibers were restricted to a maximum of $1 \%$ by volume fraction of fibers. To perform experimental tests for each water-cement ratio, for compressive strength 21 cubic specimens with dimensions of $100 \times 100 \times 100 \mathrm{~mm}$, for tensile strength 14 cylindrical specimens with dimensions of $150 \times 300 \mathrm{~mm}$ and flexural strength 14 prismatic specimens $100 \times 100 \times 500 \mathrm{~mm}$ are prepared in the laboratory environment. In this research, only the carboxylate superplasticizer was added in the concrete mixtures, and two types of fibers are used. For compressive strength ASTM C-39 [[28]], for tensile strength ASTM C-496 [[29]] and for flexural strength test, ASTM C-293-08 [[30]] standards are selected.

\section{MATERIALS AND FIBERS PROPERTIES}

1 he cement of the specimens is provided from the Hekmatan cement factory in Hamedan city. The water used in the mixtures was used from the Hamedan drinking water distribution system with a $\mathrm{pH}$ equal to 6.5 and with a chloride ion concentration $0.013 \%$. The superconductor polycarboxylate is added to mixtures for increasing the performance of the concrete. The range of polycarboxylate was between 0.20 to $1.50 \%$ by weight of the cement. Sand is used with density and water absorption equal to $2.56 \mathrm{~g} / \mathrm{cm}^{3}$ and $3.52 \%$, respectively, according to the ASTM C-128 standard 
[[31]]. Fine aggregate (sand) with a 3.4 fineness modulus and coarse aggregate (gravel) with a maximum particle size of 19 $\mathrm{mm}$ were used in the specimens. According to the ASTM C-127 standard [[32]], density and water absorption of coarse aggregate equal to $2.684 \mathrm{~g} / \mathrm{cm}^{3}$ and $1.01 \%$, respectively. The mechanical properties of the steel and glass fibers are summarized in Tab. 1. Also, Fig. 1 shows the shape and size of applied glass and steel fibers in this study.

\begin{tabular}{ccccccc}
\hline Standard & Fiber & Shape & $\begin{array}{c}\text { Diameter } \\
\left(\mathrm{g} / \mathrm{cm}^{3}\right)\end{array}$ & $\begin{array}{c}\text { Diameter } \\
(\mathrm{mm})\end{array}$ & $\begin{array}{c}\text { Length } \\
(\mathrm{mm})\end{array}$ & L/D \\
ASTM-A820 & steel & Hooked-end & 7.85 & 0.80 & 50 & 62.5 \\
ASTM D790 & glass & straight & 2.60 & 0.019 & 12 & 631.6 \\
\hline
\end{tabular}

Table 1: Specifications of the steel fibers and glass

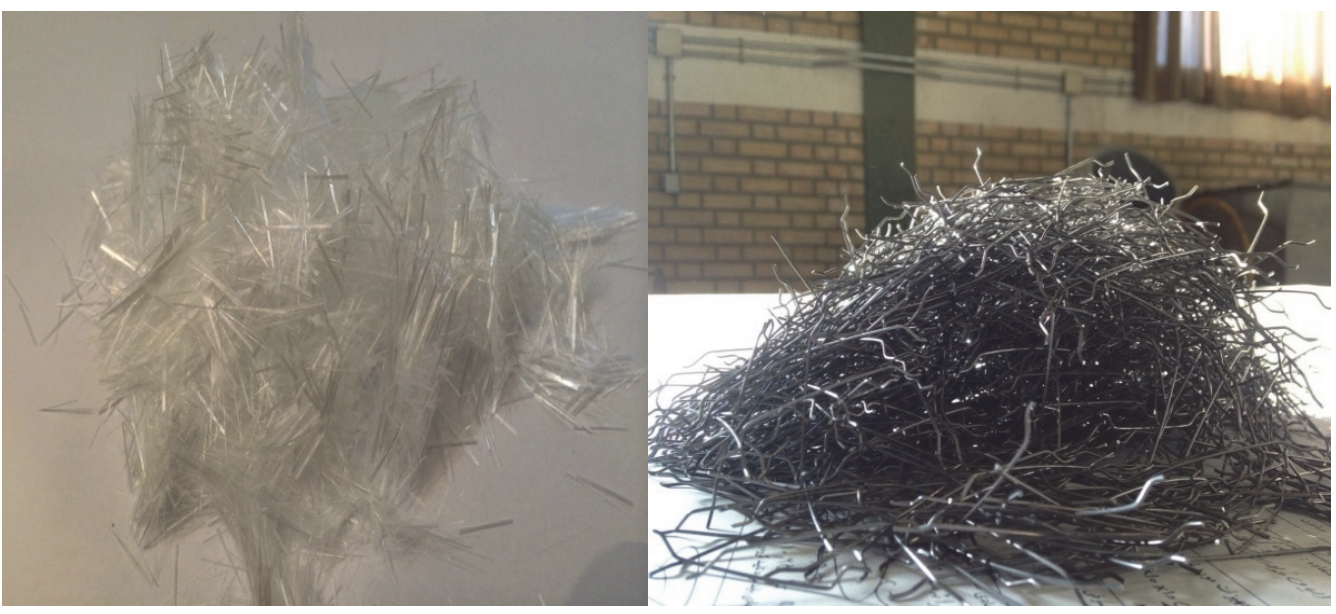

Figure 1: Shape and geometry of steel fibers (left) and glass fibers (right).

\section{Concrete mixing procedure}

Ordinary Portland cement (ASTM Type 2), produced by the Hekmatan cement factory, was used. Additionally, coarse aggregate with the maximum particle size equal to $19 \mathrm{~mm}$ and also fine aggregate with a 3.4 fineness modulus was used in this research. The specific gravity and water absorption of the coarse and fine aggregates were 2.65 and $0.56 \%$, and 2.61 and $1.92 \%$, respectively. Polycarboxylate with a commercial brand called LG is used in mixtures for increasing the workability of the concrete. Hooked-end steel fibers with a length of $50 \mathrm{~mm}$ and a diameter of $0.80 \mathrm{~mm}$ were employed in this study.

\section{Preparing of specimens \& molding}

The trial and error approach was used for the mixing procedure, and it was chosen as follows: the binder and fine aggregates were mixed 70 seconds, and nearly half of the water and the superplasticizer were mixed for 150 seconds. The rest of the required water and coarse aggregate was added and then mixed for about 6 min. Finally, selected fibers were added to the mixtures and then mixed for 6 min again to better mixing with concrete. The mixing procedure was designed to facilitate the spreading of the fibers in the mixtures. Each type of fresh concrete was cast into cubic $(100 \times 100 \times 100 \mathrm{~mm})$, cylindrical $(150 \times 300 \mathrm{~mm})$ and prismatic $(100 \times 100 \times 500 \mathrm{~mm})$ respectively. Before de-molding, all specimens were stored at $23^{0 \mathrm{C}}$ and $100 \%$ relative humidity for $24 \pm 2$ hours. The concrete specimens were cured in lime-saturated water until testing. To convenient labeling to specimens, the name of each design is coded as follows: $\mathrm{C}$ refers to concrete; $\mathrm{N}$ is normal or plain concrete; $\mathrm{S}$ is steel fiber, and $\mathrm{F}$ is glass fiber. Tab. 2 presents the labeling of the specimens in this research. There are seven different specimens in this research for each water- to- cement ratio. To perform the experimental tests for each watercement ratio, 21 cubic specimens for compressive strength, 14 cylindrical specimens for tensile strength test, and finally, 14 prismatic specimens for flexural strength test are designed. Therefore, to conduct this research, 96 specimens are prepared. The proportion of required materials for W/C equal to 0.35 and 0.45 . e.g., water, cement, sand, gravel, and also superplasticizer in the concrete mixtures are summarized in Tab. 3. 


\begin{tabular}{cc}
\hline Code & \multicolumn{1}{c}{ Description } \\
CN & Normal concrete ( no fibers) \\
CSF0.3 & Concrete $+0.3 \%$ steel fiber \\
CSF0.6 & Concrete $+0.6 \%$ steel fiber \\
CSF0.9 & Concrete $+0.9 \%$ steel fiber \\
CGF0.3 & Concrete $+0.3 \%$ glass fiber \\
CGF0.6 & Concrete $+0.6 \%$ glass fiber \\
CGF0.9 & Concrete $+0.3 \%$ glass fiber \\
\hline
\end{tabular}

Table 2: Labeling of the prepared specimens in this research.

\begin{tabular}{cccccccccc}
\hline & $\mathrm{W} / \mathrm{c}$ & $\mathrm{CN}$ & CSF0.3 & CSF0.6 & CSF0.9 & CGF0.3 & CGF0.6 & CGF0.9 \\
Water $(\mathrm{kg})$ & 0.35 & 140 & 140 & 140 & 140 & 140 & 140 & 140 \\
& 0.45 & 157.5 & 157.5 & 157.5 & 157.5 & 157.5 & 157.5 & 157.5 \\
Cement $(\mathrm{kg})$ & 0.35 & 400 & 400 & 400 & 400 & 400 & 400 & 400 & 350 \\
& 0.45 & 350 & 350 & 350 & 350 & 350 & 350 & 980 & 980 \\
Sand (kg) & 0.35 & 980 & 980 & 980 & 980 & 980 & 975 & 975 & 975 \\
Fine Gravel & 0.45 & 975 & 975 & 975 & 975 & 975 & 362 & 362 \\
Coarse Gravel & 0.35 & 362 & 362 & 362 & 362 & 362 & 360 & 360 & 360 \\
Fibers & 0.45 & 360 & 360 & 360 & 360 & 560 & 561 \\
& 0.35 & 561 & 561 & 561 & 561 & 561 & 561 & 559 & 559 \\
Superplastizer & 0.45 & 559 & 559 & 559 & 559 & 559 & 559 & 23.5 \\
& 0.35 & - & 23.5 & 23.5 & 23.5 & 23.5 & 23.5 & 23.5 \\
& 0.45 & - & 23.5 & 47.1 & 70.6 & 8.4 & 16.8 & 25.2 \\
\hline
\end{tabular}

Table 3: Concrete mixtures components $\left(\mathrm{kg} / \mathrm{m}^{3}\right)$ for $\mathrm{W} / \mathrm{C}$ ratios equal to 0.35 and 0.45 .

\section{Compressive strength test}

The compressive strengths of the specimens were determined at the ages of 7 and 28 days, according to the mentioned standard. For this purpose, at each age, three cubic $100 \times 100 \times 100 \mathrm{~mm}$ samples were used to report their mean compressive strength values. The specimens were cured in a water pond at a temperature of about $23^{\circ C}$ until the age of testing. The ADR 2000 hydraulic press machine with a capacity of $2000 \mathrm{kN}$ with loading speed equal to $3 \mathrm{kN}$ per second was used under the ASTMC39 standard [[28]] to determine the compressive strength.

\section{Tensile strength test}

According to the ASTM-C496 standard [[29]], this experiment was performed at 28 days for cylindrical specimens with a diameter of $150 \mathrm{~mm}$ and a height of $300 \mathrm{~mm}$. It should be noted that the ADR hydraulic press machine with a capacity of $2000 \mathrm{kN}$ and loading speed equal to $0.94 \mathrm{kN}$ per second was used for this test (Fig. 2). The splitting tensile strength is calculated from Eq.(1). 


$$
\mathrm{T}=\frac{2 \mathrm{P}}{\pi \mathrm{DL}}
$$

where $T$ is the splitting tensile strength $(\mathrm{MPa}), P$ is the maximum applied load $(\mathrm{N}), L$ is the distance between the supports $(\mathrm{mm})$, and $D$ is the sample diameter $(\mathrm{mm})$.

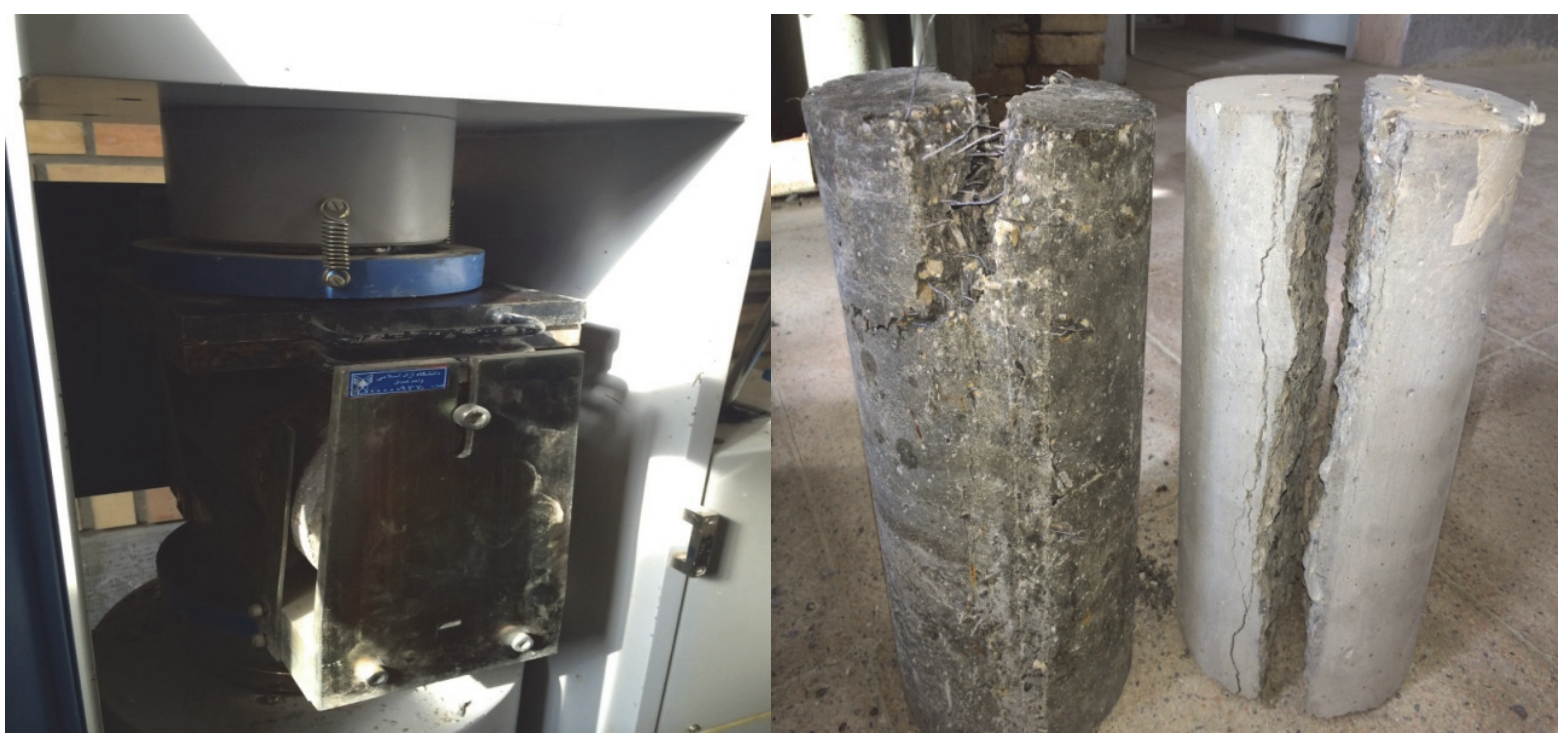

Figure 2: Tensile strength test by the splitting method (left) and failure geometry of specimens (right).

\section{Flexural strength test}

After currying of concrete containing glass and steel fibers at the age of 28 -days, the flexural test of $100 \times 100 \times 500 \mathrm{~mm}$ samples was carried out according to ASTM C-293-08 standard [[30]]. It should be noted that the GOTECH testing machine Gt-TCS-2000 model is used for this text. The distance between the two supports was $300 \mathrm{~mm}$ for failing the specimen, and the rate of loading was $1 \mathrm{~mm}$ per minute. Fig. 3 presents the flexural test and failure of the sample.

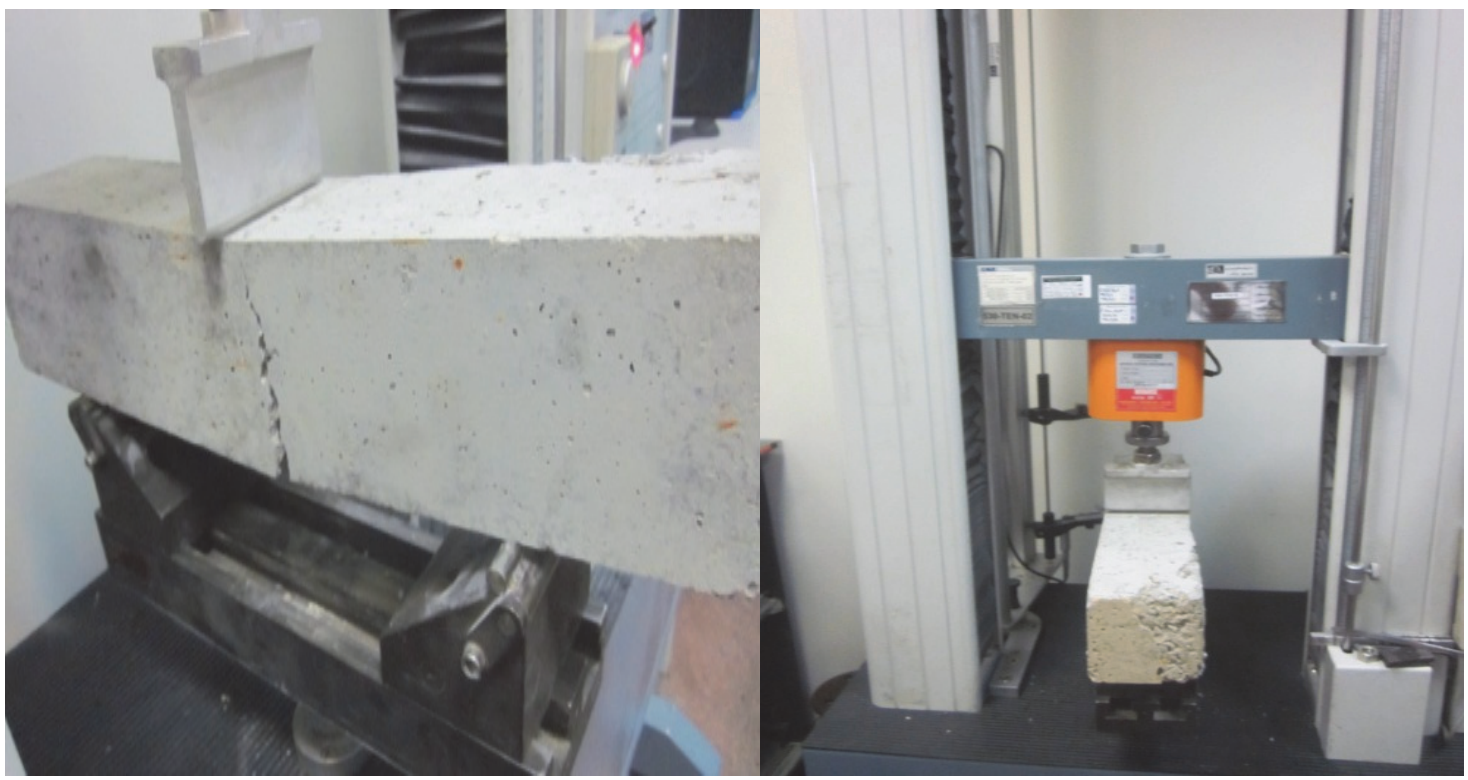

Figure 3: Flexural three-point test (left) and failure of the sample (right)

According to the ASTM C-293-08 standard [[30]], the flexural strength of specimens is obtained with Eq.(2). 


$$
\mathrm{f}_{\mathrm{r}}=\frac{3 \mathrm{PL}}{2 \mathrm{bd} \mathrm{d}^{2}}
$$

where $f_{r}$ refers to the failure strength (MPa), $P$ is the maximum applied load by hydraulic jack $(N), L$ is the distance between

\begin{tabular}{|c|c|c|c|c|c|c|c|c|c|c|c|}
\hline \multirow[b]{2}{*}{ 范 } & \multirow[b]{2}{*}{$\frac{\cup}{\geqslant}$} & \multicolumn{2}{|c|}{$\mathrm{f}_{\mathrm{c}}^{\prime}(\mathrm{MPa})$} & \multicolumn{2}{|c|}{$\mathrm{f}_{\mathrm{t}}(\mathrm{MPa})$} & \multicolumn{2}{|c|}{$\mathrm{f}_{\mathrm{r}}(\mathrm{MPa})$} & \multicolumn{2}{|c|}{$\left(f_{t} / f_{c}^{\prime}\right) \times 100$} & \multicolumn{2}{|c|}{$\left(f_{t} / f_{r}\right) \times 100$} \\
\hline & & 7-day & 28- day & 7-day & 28 days & 7-day & 28 days & 7-day & 28 days & 7-day & 28 days \\
\hline \multirow{2}{*}{$\mathrm{CN}$} & 0.35 & 22.84 & 37.12 & 1.88 & 3.03 & 3.05 & 4.91 & 8.2 & 8.2 & 62 & 62 \\
\hline & 0.45 & 21.61 & 30.88 & 1.67 & 2.49 & 2.51 & 3.96 & 7.7 & 8.0 & 50 & 63 \\
\hline \multirow{2}{*}{ CSF0.3 } & 0.35 & 32.20 & 45.36 & 2.26 & 3.41 & 3.75 & 5.31 & 7.0 & 7.5 & 60 & 64 \\
\hline & 0.45 & 26.17 & 37.93 & 1.74 & 2.76 & 2.81 & 4.30 & 6.7 & 7.3 & 62 & 64 \\
\hline \multirow{2}{*}{ CSF0.6 } & 0.35 & 34.81 & 50.44 & 2.62 & 3.91 & 4.74 & 7.38 & 7.5 & 7.8 & 55 & 53 \\
\hline & 0.45 & 29.73 & 41.29 & 2.14 & 3.06 & 4.15 & 5.85 & 7.2 & 7.4 & 52 & 52 \\
\hline \multirow{2}{*}{ CSF0.9 } & 0.35 & 38.32 & 53.81 & 3.12 & 4.46 & 5.94 & 8.48 & 8.1 & 8.3 & 53 & 53 \\
\hline & 0.45 & 32.31 & 45.51 & 2.66 & 3.52 & 4.88 & 6.78 & 8.2 & 7.7 & 55 & 52 \\
\hline \multirow{2}{*}{ CGF0.3 } & 0.35 & 28.89 & 41.87 & 2.24 & 3.18 & 3.61 & 5.13 & 7.8 & 7.6 & 62 & 62 \\
\hline & 0.45 & 23.73 & 32.96 & 1.88 & 2.55 & 3.00 & 4.19 & 7.9 & 7.7 & 63 & 61 \\
\hline \multirow{2}{*}{ CGF0.6 } & 0.35 & 30.66 & 42.59 & 2.76 & 3.75 & 4.61 & 6.26 & 9.0 & 8.8 & 60 & 60 \\
\hline & 0.45 & 22.92 & 32.22 & 2.13 & 2.89 & 3.66 & 5.07 & 9.3 & 9.0 & 58 & 57 \\
\hline \multirow{2}{*}{ CGF0.9 } & 0.35 & 25.20 & 36.52 & 2.81 & 4.13 & 5.00 & 7.13 & 11.2 & 11.3 & 56 & 58 \\
\hline & 0.45 & 20.05 & 28.24 & 2.65 & 3.31 & 4.22 & 5.88 & 13.2 & 11.7 & 63 & 56 \\
\hline
\end{tabular}

the supports (mm). Parameters $b$ and $d$ are the average width and the effective depth of the sample at the moment of failure (mm), respectively.

Table 4: Mechanical properties of designs for W/C equal to 0.35 and 0.45 at the ages of 7 and 28 days

\section{RESULTS}

$\mathrm{I}$ $\mathrm{n}$ this section, according to Tab. 4 , the results of compressive, tensile, and flexural tests for steel and glass fibers in water to cement ratios equal to 0.35 and 0.45 are summarized. As well, the last four columns of Tab. 4 refer to ratios of tensile to compressive and tensile to flexural strengths, respectively. Hereafter, the results for all seven designs, according to Tab. 2, are presented graphically for the age of 28 days only. The results for the age of 7 days could be followed in Tab. 4.

\section{Compressive strength}

Fig. 4 demonstrates the results of the compressive tests for water to cement ratio equal to 0.35 and 0.45 at the ages of 28 days

Fig. 4 shows that at this age, for both water-to-cement ratios, increasing compressive strength for steel fiber is more than glass fiber. As well, adding steel fibers say up to $0.9 \%$ by volume fraction, increases the compressive strength, but adding glass fiber more than $0.6 \%$ to $0.9 \%$ the strengths decrease. The reason for decreasing strength for glass fiber is the nonuniform dispersion of the fibers during mixing. Besides, the figure reveals that steel fibers have a significant effect than glass fibers to increase the compressive strengths of all specimens.

\section{Tensile strength}

Fig. 5 depicts the tensile strength for the specimens at the age of 28 days for the water to cement ratios equal to 0.35 and 0.45 . As can be seen from this figure, by adding steel and glass fibers in the range of $0.3 \%$ to $0.9 \%$ by volume of concrete, 
the tensile strengths of all samples were gradually increased in both $\mathrm{W} / \mathrm{C}$ ratios. The reason for increased tensile strength is that normal concrete is brittle, and adding fibers reduces the brittle behavior of concrete and also prevents crack propagation in the concrete. This figure illustrates that the effect of steel fiber is nearly similar to the effect of glass fiber to enhance the tensile strength in all specimens. For both fibers, adding steel and glass fibers up to $0.9 \%$ steadily increased the tensile strengths.

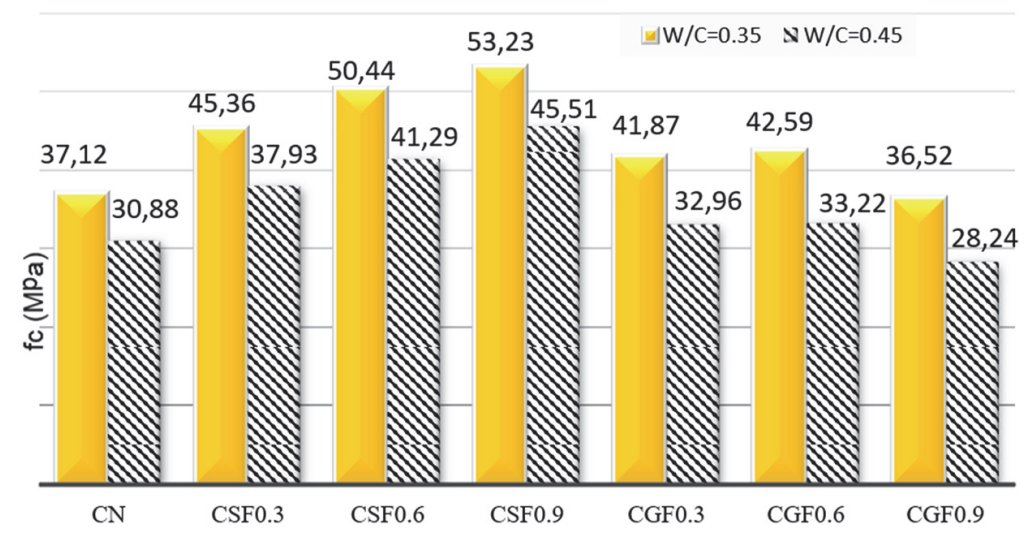

Figure 4: Compressive strengths of specimens at the age of 28 days for W/C equal to 0.35 and 0.45 .

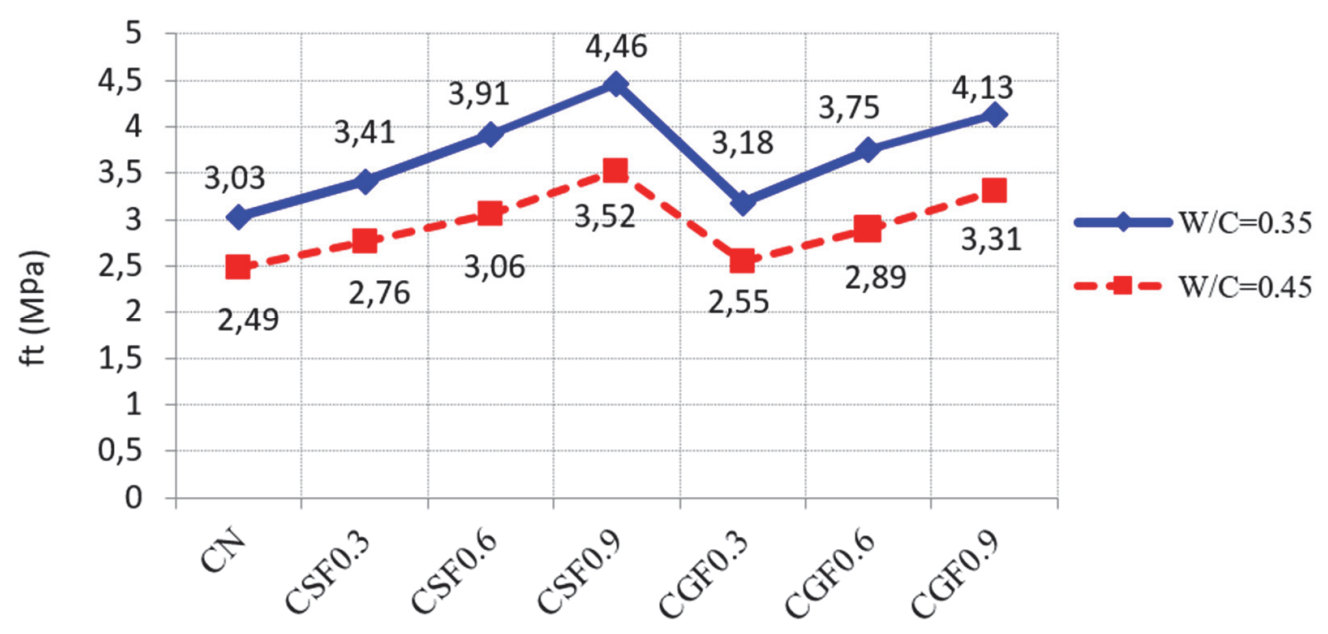

Figure 5: Comparison of tensile strength at the age of 28 days

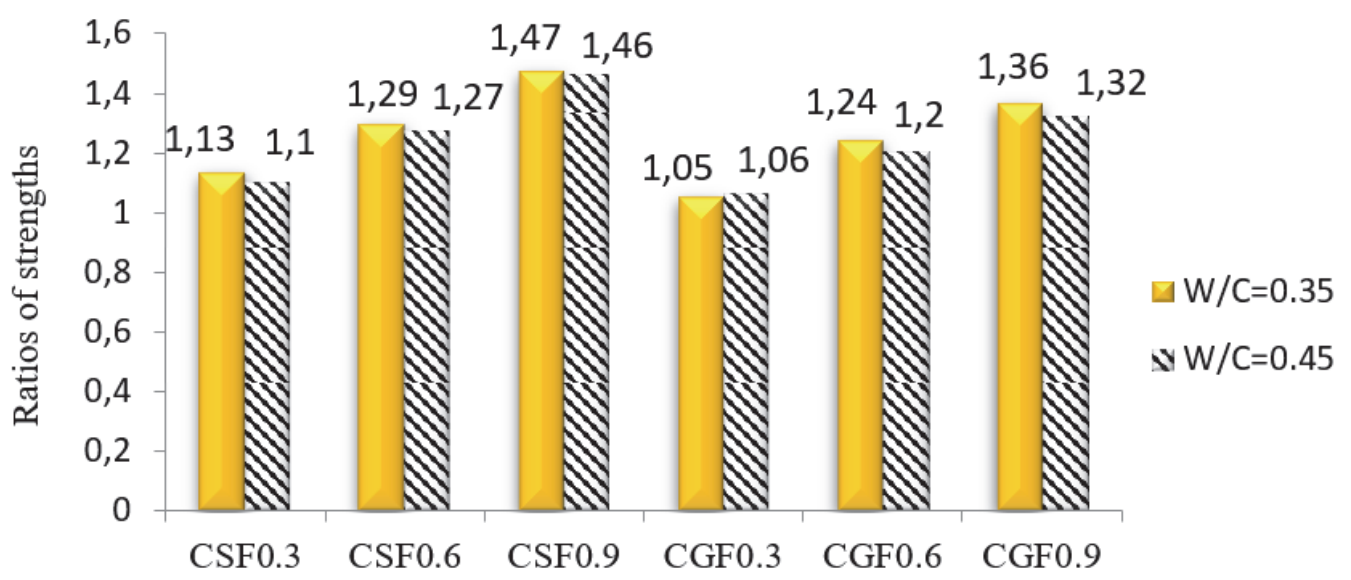

Figure 6: Ratios of the tensile strength of fiber-reinforced concrete to normal concrete 
As well, Fig. 6 illustrates the ratios of the tensile strength of concrete with fibers to plain concrete (without fiber) in both water to cement ratios at the age of 28 days. The figure shows that adding $0.9 \%$ steel fiber and glass fiber increase nearly $47 \%$ and $36 \%$ of tensile strength, respectively. As well, adding $0.3 \%$ and $0.9 \%$ fibers has the minimum and maximum effect on tensile strength in both w/c ratios, respectively. The graph reveals that adding fibers has a similar impact on strength increasing for both water-to cement-ratios.

\section{Flexural strength}

Fig. 7 displays the flexural strength of the designs in 28-day aging for water to cement ratios 0.35 and 0.45 . As it is observed from Fig. 8, by adding both steel and glass fibers in the range of $0.3 \%$ to $0.9 \%$ by volume fraction of concrete, the flexural strengths of the samples were steadily increased for both W/C ratios. Additionally, the results show that the performance of steel fiber is better than glass fiber.

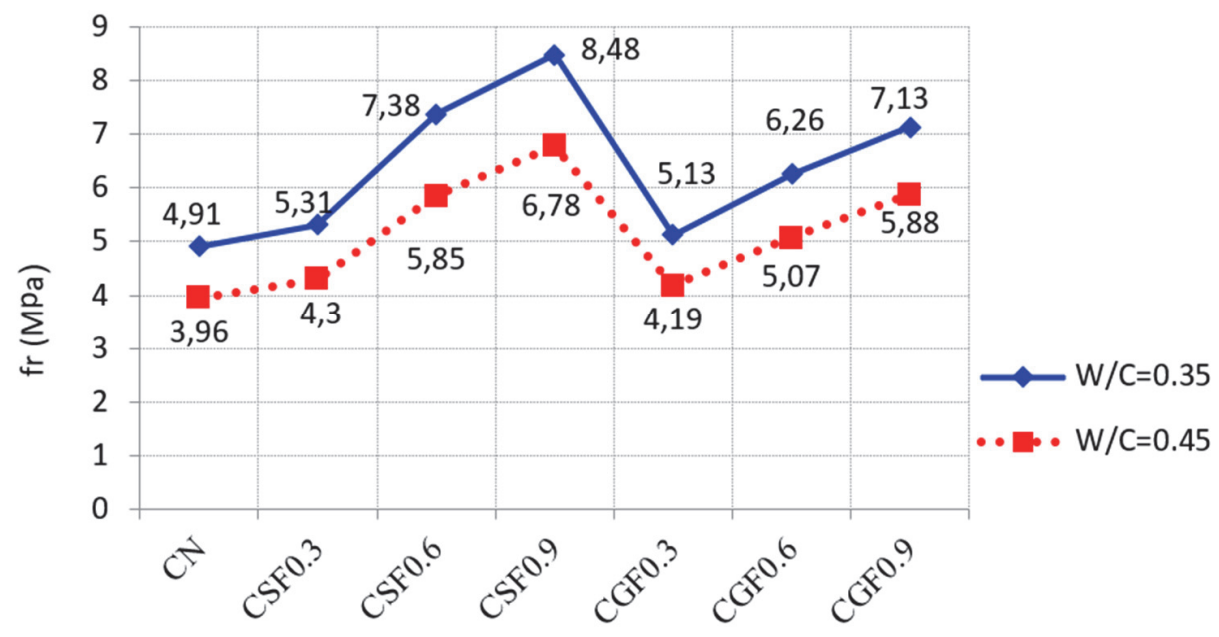

Figure 7: Comparison of flexural strength of specimens at 28 days of aging

As well, Fig. 8 exhibits the ratios of flexural strengths of fiber-concrete to plain concrete (without fiber) in both water-tocement ratios. The figure shows that adding $0.9 \%$ steel fiber and glass fiber increase nearly $73 \%$ and $49 \%$ of flexural strength, respectively. As well, adding $0.3 \%$ and $0.9 \%$ fibers has the minimum and maximum effect on flexural strength in both $\mathrm{W} / \mathrm{C}$ ratios, respectively. The graph reveals the effect of water-to cement-ratio has no significant impact on the increase of flexural strengths in specific concrete containing fiber with respect to plain concrete. For example, consider ratios 1.73 with 1.71 in CSF0.9 specimen. The graph reveals that steel fibers have more influence than glass fiber in increasing the flexural strength. For instance, compare the numbers 1.73 and 1.71 for CSF0.9 with 1.45 and 1.49 for CGF0.9.

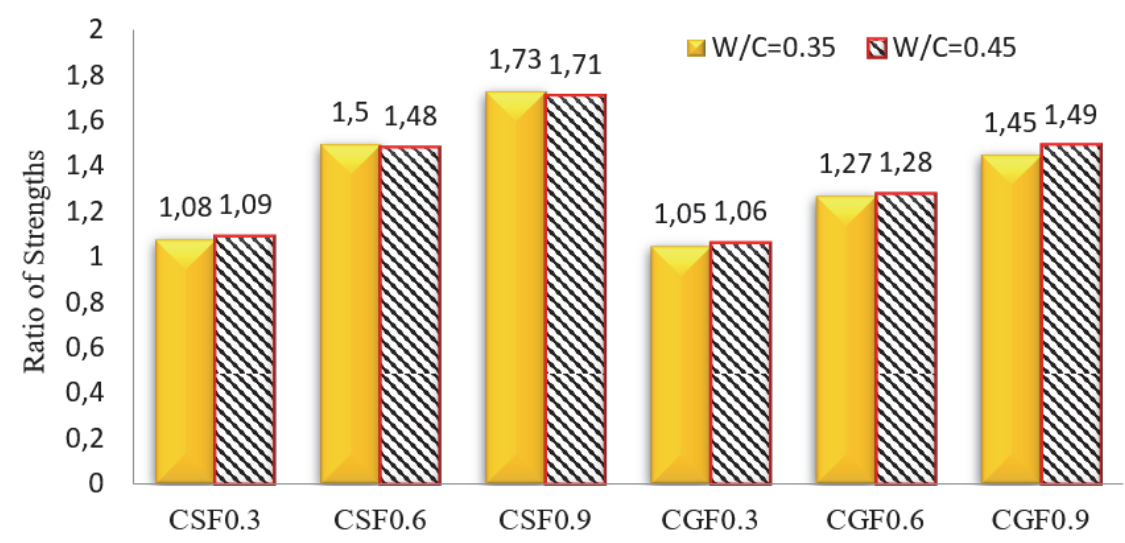

Figure 8: Ratios of flexural strengths of fiber-reinforced concrete to plain concrete

The effect of the reduction of water to cement ratio for increasing flexural strength is investigated in Fig. 9. According to the flexural test results, as shown in Fig. 8, the effect of fibers in comparison with water to cement ratio is more important 
in the enhancement of flexural strengths. As shown in Fig. 9, the flexural strength ratio of fiber concrete with water to cement ratio of 0.35 to 0.45 was investigated. As seen from this figure, usually by reduction of water-to-cement from 0.45 to 0.35 in all designs, more than $24 \%$ increasing in flexural strengths are observed. On the other hand, with a reduction of 0.10 in water-to cement ration, an average increasing $24 \%$ (mean ratios in Fig. 9) in flexural strength is observed.

$0.35 / 0.45$

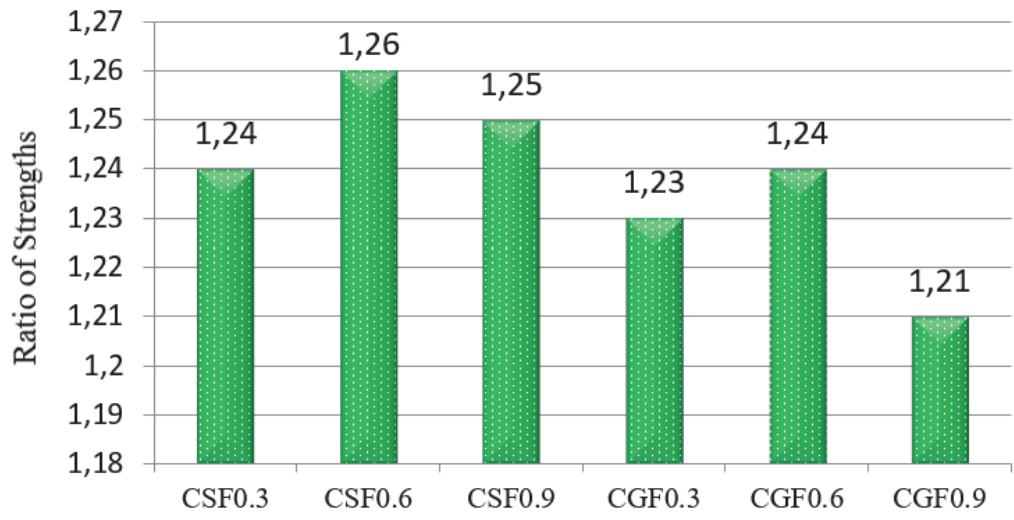

Figure 9: Effect of ratios of $\mathrm{w} / \mathrm{c}=0.35$ and $\mathrm{w} / \mathrm{c}=0.45$ in increasing flexural strengths

\section{Relation of tensile strength with compressive strength}

The tensile strength of concrete is expressed as a percentage of the compressive strength. This percentage is usually reported in the range of $8 \%$ to $15 \%$. In this study, the ratio of tensile strength to compressive strength at the age of 28 -day plain and fiber concrete is presented in Fig. 10.

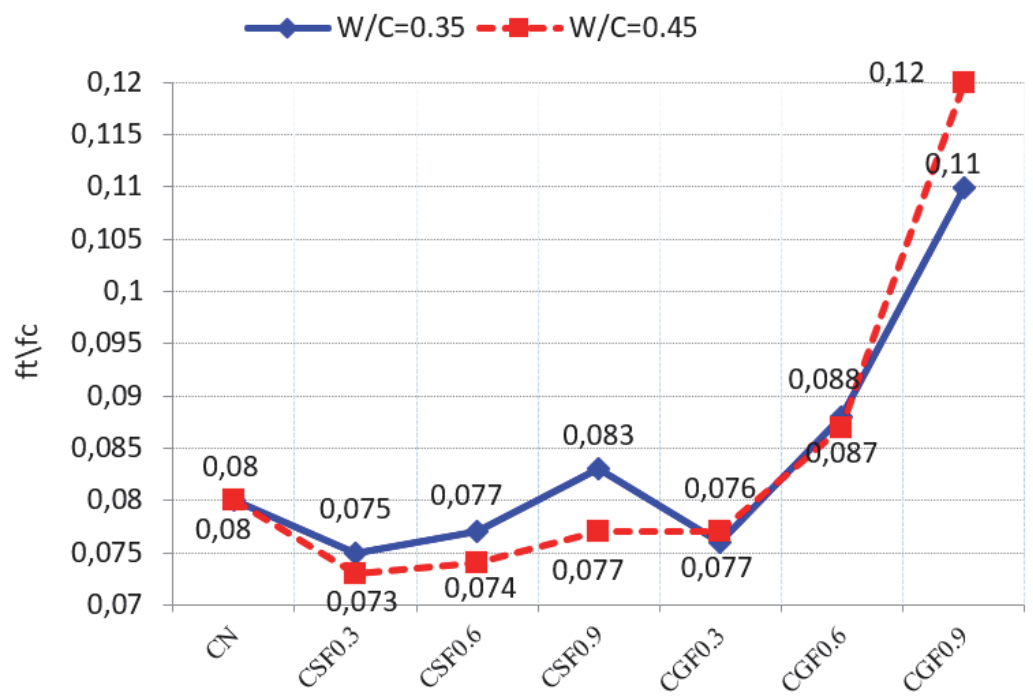

Figure 10: Ratios of tensile strength to compressive strength at the age of 28-day.

As can be seen from Fig.10, the mean ratio of tensile strength to compressive strength is about $8.5 \%$ for W/C equal to 0.35 and $8.3 \%$ for $\mathrm{W} / \mathrm{C}$ equal to 0.45 . However, in glass fiber concrete with $0.9 \%$ fiber (CGF0.9), this ratio has been reached $11 \%$. Therefore, in practical application, the lower bond value $8 \%$ is preferable than the upper bond value of $15 \%$. As a result, as a practical application, confidently equation $\mathrm{f}_{\mathrm{t}}=0.08 \mathrm{f}_{\mathrm{c}}{ }_{\mathrm{c}}$ is recommended. In which $\mathrm{f}_{\mathrm{t}}$ is tensile strength and $\mathrm{f}_{\mathrm{c}}{ }^{\prime}$ is the compressive strength of plain and reinforced concrete for the age of 28 days. As well, the ratios of tensile strengths to flexural strengths for seven designs at the age of 28 days in water to cement ratios equal to 0.35 and 0.45 illustrated in Fig. 11.

As can be seen from Fig.11, the mean ratio of tensile strength to flexural strength is about $60 \%$ for both W/C equal to 0.35 and 0.45 . However, in steel fiber concrete with $0.6 \%$ and $0.9 \%$ fibers (CSF0.6, CSF0.9), this ratio has been reached the 
lowest value equal to $52 \%$. For both fibers, in $0.3 \%$, the ratios of tensile strength to flexural strength are in the highest value of about $62 \%$. As an approximate estimation, we can say $\mathrm{f}_{\mathrm{r}}=1.60 \mathrm{f}_{\mathrm{t}}$ and $\mathrm{f}_{\mathrm{r}}=0.13 \mathrm{f}_{\mathrm{c}}^{\prime}$.

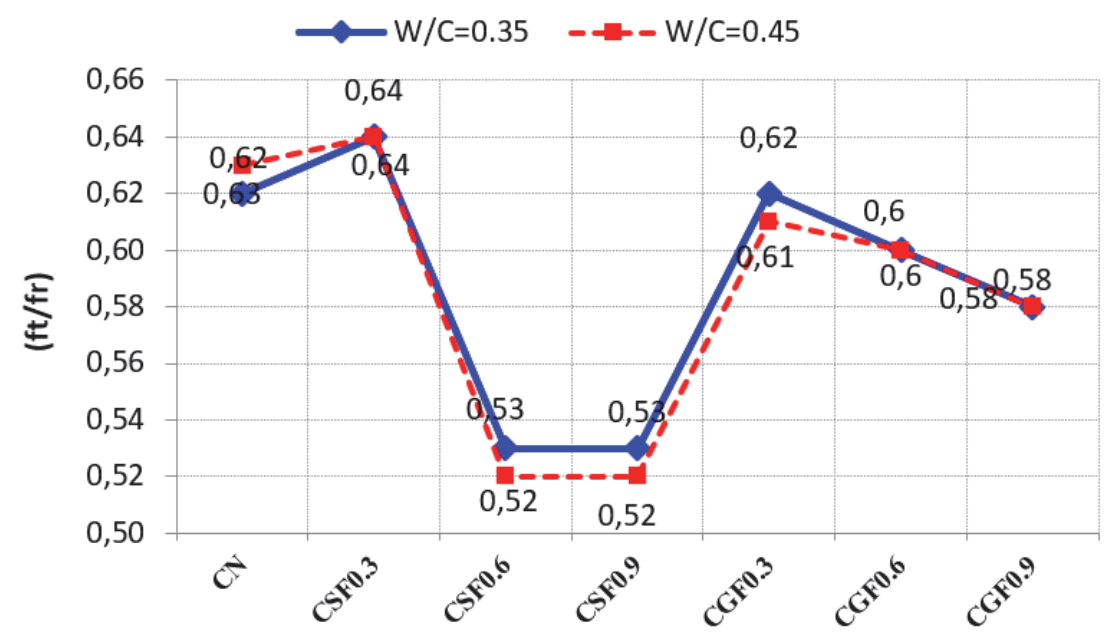

Figure 11: Ratios of tensile strength to flexural strength at the age of 28 days

\section{CONCLUSIONS}

$\mathrm{I}$ $\mathrm{n}$ the present paper, the behavior of plain and fiber-reinforced concretes is experimentally studied. The effects of waterto-cement and steel and glass fibers on compressive, tensile, and flexural strengths were investigated. According to the results of this study, the following conclusions could be drawn;

- The presence of steel fibers in concrete with $0.3 \%$ to $0.9 \%$ fraction volume of concrete increases the compressive, tensile, and flexural strengths for both water- to- cement ratios. Glass fibers only increase compressive strength in the range of $0.3 \%$ to $0.6 \%$ and using more than this value decreases compressive strength. By increasing glass fibers up to $0.9 \%$, tensile and flexural strengths are also increased.

- The steel fibers have better performance in comparison with glass fibers in all cases. Therefore, based on the results of this study, the authors suggest that adding steel fiber is preferable than adding glass fiber. If, for any reason, the fibers are not available, the reduction of water-to-cement- ratio is recommended instead of adding fibers to improve the mechanical properties of concrete.

- Using concrete containing steel fibers is preferable than glass fibers due to the lack of water absorption and the proper spreading of steel fibers.

- The tensile strength and flexural strength of concrete could be approximately explained as $8 \%$ and $13 \%$ of compressive strength, respectively.

In practical applications, for designers $\mathrm{f}_{\mathrm{t}}=0.08 * \mathrm{f}_{\mathrm{c}}{ }_{\mathrm{c}}$ and $\mathrm{f}_{\mathrm{r}}=0.13 * \mathrm{f}_{\mathrm{c}}{ }^{\prime}$ is recommended

\section{CONFLICTS OF INTEREST}

here is no conflict of interest to declare.

\section{REFERENCES}

[1] ACI Committee 544 (1996), State-of-the-art report on fiber-reinforced concrete, report 544.1R-96 American Concrete Institute, Detroit. 
[2] Patil, T. R., \& Burile, A. N. (2013). Comparative study of steel and glass fiber reinforced concrete composites. International Journal of Science and Research, 5(5), pp. 690-694.

[3] Kaikea, A., Achoura, D., Duplan, F., \& Rizzuti, L. (2014). Effect of mineral admixtures and steel fiber volume contents on the behavior of high-performance fiber reinforced concrete. Materials \& Design, 63, pp. 493-499.

[4] Wille, K., Tue, N. V., \& Parra-Montesinos, G. J. (2014). Fiber distribution and orientation in UHP-FRC beams and their effect on backward analysis. Materials and Structures, 47(11), pp. 1825-1838.

[5] Nili, M., Azarioon, A., Danesh, A., \& Deihimi, A. (2018). Experimental study and modeling of fiber volume effects on frost resistance of fiber reinforced concrete. International Journal of Civil Engineering, 16(3), pp. 263-272.

[6] Liu, H. D., Yu, X. Z., \& Li, G. W. (2005). Experimental study on tensile mechanical properties of glass fiber reinforced plastic rebar. Chinese Journal of Rock Mechanics and Engineering, 20.

[7] Ganesan, N., Indira, P. V., \& Santhakumar, A. (2014). Influence of steel fibers on tension stiffening and cracking of reinforced geopolymer concrete. Magazine of concrete research, 66(6), pp. 268-276.

[8] Ashour, S. A., Hasanain, G. S., \& Wafa, F. F. (1992). Shear behavior of high-strength fiber reinforced concrete beams. Structural Journal, 89(2), pp. 176-184.

[9] Kwak, Y. K., Eberhard, M. O., Kim, W. S., \& Kim, J. (2002). Shear strength of steel fiber-reinforced concrete beams without stirrups. ACI Structural Journal, 99(4), pp. 530-538.

[10] Soutsos, M. N., Le, T. T., \& Lampropoulos, A. P. (2012). Flexural performance of fiber-reinforced concrete made with steel and synthetic fibers. Construction and building materials, 36, pp. 704-710.

[11] Aldossari, K. M., Elsaigh, W. A., \& Shannag, M. J. (2014). Effect of steel fibers on flexural behavior of normal and high strength concrete. International Journal of Civil and Environmental Engineering, 8(1), pp. $22-26$.

[12] Wille, K., \& Parra-Montesinos, G. J. (2012). Effect of Beam Size, Casting Method, and Support Conditions on Flexural Behavior of Ultra-High-Performance Fiber-Reinforced Concrete. ACI Materials Journal, 109(3), 379.

[13] Meng, W., \& Khayat, K. H. (2016). Experimental and numerical studies on the flexural behavior of ultrahighperformance concrete panels reinforced with embedded glass fiber-reinforced polymer grids. Transportation Research Record, 2592(1), pp. 38-44.

[14] Kushartomo, W., \& Ivan, R. (2017). Effect of Glass Fiber on Compressive, Flexural and Splitting Strength of Reactive Powder Concrete. In MATEC Web of Conferences, 138, p. 03010.

[15] Chalioris, C. E. (2013). The analytical approach for the evaluation of minimum fiber factor required for steel fibrous concrete beams under combined shear and flexure. Construction and Building Materials, 43, pp. 317-336.

[16] Yoo, D. Y., Kang, S. T., \& Yoon, Y. S. (2014). Effect of fiber length and placement method on flexural behavior, tension-softening curve, and fiber distribution characteristics of UHPFRC. Construction and Building materials, 64, pp. 67-81.

[17] Sivakumar, A., \& Santhanam, M. (2007). Mechanical properties of high strength concrete reinforced with metallic and non-metallic fibers. Cement and Concrete Composites, 29(8), 603-608.

[18] Xu, B. W., \& Shi, H. S. (2009). Correlations among mechanical properties of steel fiber reinforced concrete. Construction and Building Materials, 23(12), pp. 3468-3474.

[19] Chandramouli, K., Srinivasa, R. P., Pannirselvam, N., Seshadri, S. T., \& Sravana, P. (2010). Strength properties of glass fiber concrete. ARPN Journal of Engineering and Applied sciences, 5(4), pp. 1-6.

[20] Nili, M., \& Afroughsabet, V. (2010). The effects of silica fume and polypropylene fibers on the impact resistance and mechanical properties of concrete. Construction and Building Materials, 24(6), pp. 927-933.

[21] Bhikshma, V., \& Manipal, K. (2012). Study on mechanical properties of recycled aggregate concrete containing steel fibers.

[22] Etcheverry, M., \& Barbosa, S. E. (2012). Glass fiber reinforced polypropylene mechanical properties enhancement by adhesion improvement. Materials, 5(6), pp. 1084-1113.

[23] Kamal, M. M., Safan, M. A., Etman, Z. A., \& Kasem, B. M. (2014). Mechanical properties of self-compacted fiber concrete mixes. HBRC Journal, 10(1), pp. 25-34.

[24] Ashik, K. P., \& Sharma, R. S. (2015). A review of the mechanical properties of natural fiber reinforced hybrid polymer composites. Journal of Minerals and Materials Characterization and Engineering, 3(05), 420.

[25] Saba, N., Paridah, M. T., \& Jawaid, M. (2015). Mechanical properties of kenaf fiber reinforced polymer composite: A review. Construction and Building materials, 76, pp. 87-96.

[26] Ibrahim, K. I. M. (2016). Mechanical properties of glass fiber reinforced concrete (GFRC). Journal of Mechanical and Civil Engineering, 13(4).

[27] Ahmadi, M., Farzin, S., Hassani, A., \& Motamedi, M. (2017). Mechanical properties of the concrete containing recycled fibers and aggregates. Construction and Building Materials, 144, pp. 392-398. 
[28] ASTM International. ASTM C39. (2010). Standard test method for compressive strength of cylindrical concrete specimens.

[29] ASTM International. ASTM C496. (2011). Test Method for Splitting Tensile Strength of Cylindrical Concrete Specimens.

[30] ASTM International. ASTM C293-08 (2008). Standard test method for Flexural strength of concrete (Using Simple Beam White Center-Point loading).

[31] ASTM International. (2012). ASTM C128: Standard Test Method for Density, Relative Density (Specific Gravity), and Absorption of Fine Aggregate.

[32] ASTM International. (2012). ASTM C127: Standard Test Method for Density, Relative Density (Specific Gravity), and Absorption of Coarse Aggregate. 